\title{
OCULAR PROBLEMS ASSOCIATED WITH AIR TRAVELING
}

\author{
Marek PROST ${ }^{1}$, Krzysztof KOWALCZUK ${ }^{2}$, Jaromir WASYLUK ${ }^{1}$ \\ 1 Department of Ophthalmology, Military Institute of Aviation Medicine, Warsaw, Poland \\ 2 Department of Simulator Studies and Aeromedical Training, Military Institute of Aviation Medicine, \\ Warsaw, Poland
}

Source of support: Own sources

Author's address: M. Prost, Military Institute of Aviation Medicine, Krasińskiego 54/56 Street, 01-755 Warsaw, Poland, e-mail: marekprost@wp.pl

Abstract: Air transport is the most dynamically developing branch of transport and the number of services provided by civil aviation is increasing from year to year. However, the conditions in the passenger cabin during the flight differ from those on the ground. The aim of this report is to discuss how the changed environment in the cabin affects the visual system, where eye disorders can cause or exacerbate existing ones and in which diseases traveling by air is contraindicated. Air traveling is generally safe for most passengers with eye diseases, but may cause exacerbation of some diseases of the eye and is contraindicated after some vitreoretinal operations and in the case of ischemic changes of the retina and optic nerve.

Keywords: eye diseases, air travelling, flight contraindications 


\section{INTRODUCTION}

Air transport is the most dynamically developing branch of transport and the number of services provided by civil aviation is increasing every year. Flying is also one of the safest ways to travel. According to a report by the International Air Transport Association (IATA), airlines carried a total of 4.5 billion passengers worldwide in 2019. In 2020, due to the pandemic, the number of passengers has obviously dropped drastically, but it is reasonable to believe that once the pandemic subsides, passenger transport will recover or may even increase.

The increasing availability of airplane flights means that a growing number of passengers are ophthalmic patients. How does such travel affect ocular lesions in these patients?

Ophthalmologists, occupational physicians, and primary care facilities will encounter this problem more and more often in their daily work.

The purpose of this report is to discuss how the altered cabin environment affects the organ of sight, what eye conditions it may cause or if it may worsen already existing ones, and in which diseases air travel is contraindicated.

\section{Environmental changes associated with changes of height above ground level}

As altitude changes above sea level, changes occur in the surrounding atmosphere. First of all, atmospheric pressure reduces. At sea level it averages $1013 \mathrm{hPa}$, while at 10,000 it is about 270-300 $\mathrm{hPa}$. The partial pressure of oxygen also decreases, making it less available to the body. The temperature also drops significantly; about $0.6^{\circ} \mathrm{C} / 100 \mathrm{~m}$ and at an altitude of $10,000 \mathrm{~m}$ it is between $-50^{\circ} \mathrm{C}$ and $-70^{\circ} \mathrm{C}$. Ten thousand meters above the ground, i.e. at the altitude at which passenger aircraft usually fly, the atmosphere is thinner than at its surface and therefore less protective against cosmic radiation during flight. Therefore, as altitude grows, we are more exposed to this radiation. On the route from Warsaw to New York and back, passengers are exposed to a dose of radiation equivalent to a chest X-ray, despite the fact that passengers are protected by the walls of the passenger cabin.

\section{Passenger cabin environment}

During the flight in passenger aircrafts, passenger cabins' atmospheric pressure, oxygen partial pressure and temperature are maintained artificially at levels corresponding to those prevailing on the ground to ensure comfort. However, conditions are different from those on the ground. Cabin pressure is artificially maintained at typi- cally 10.9 psi (0.75 atm), which is the same as at an altitude of about 2,400 m (8,000 ft) abovesea level. There is very low humidity in the passenger cabin (about 20-25\%, on the ground it is on average $40-50 \%)$. There is also significant movement (circulation) of air in the cabin and higher ozone concentrations [2]. Significant reduction in body mobility is also a problem. So, during an airplane flight, the passenger is in non-physiological conditions, relative to those on the ground, for several or more hours. For healthy people, this does not make much difference to their health status. However, these conditions can create problems for people with a variety of ailments, including visual impairments.

\section{Eye diseases that may occur (exacerbate) during airplane flights}

1. Dry eye syndrome. This is the most common ailment experienced by passengers during flights. It is caused by very low humidity and high air circulation in the passenger cabin. The main symptoms of dry eye syndrome are a sensation of having dry eyes, burning and red eyes, a sensation likened to that of having sand under the eyelids and eye fatigue. These discomforts can be reduced by sitting with your eyes closed, shutting the ventilation system off, frequent use of artificial tears, and keeping your body properly hydrated.

2. Ischemic neuropathy of the optic nerve. During flight, the partial oxygen pressure in the passenger cabin is slightly smaller. This causes a slight hypoxia of the eye tissues. In patients with significant vascular changes, this may result in ischemic neuropathy of the optic nerve $[7,9]$.

3. Retinal artery occlusion. Cases of retinal artery occlusion during airplane flight have been reported in the literature. These occur more frequently in patients with optic nerve drusen. They are caused by pressure of the drusen on the central retinal artery and hypoxia of the ocular tissues during flight [8].

4. Exacerbation of diabetic macular edema. Exacerbations of diabetic macular edema have been reported in the literature [4]. Their cause is retinal hypoxia during flight.

5. Neuro-Ocular Vestibular Dysfunction (NOVD). This condition is characterized by dizziness and headache, drowsiness, nausea, feeling of fatigue and heat, photophobia, clumsiness of movements, and cold sweats [11]. It is caused by imbalances in the functioning of 
the visual system, vestibular organ and deep sensibility. During flight, the vestibular system and deep sensibility relay information to the brain about the movement of our body, while the visual organ relays information about the lack of movement. NOVD can occur while traveling by air as well as by car and ship. Symptoms of the disease are somewhat lesser if the passenger sits by the window during the flight and has a seat in the part of the plane near the wings. Treatment includes medications used to treat motion sickness.

6. Eyeball pain. Eyeball pain is part of the Airplane Headache (AHA) syndrome [3]. The diagnostic criteria for this syndrome are significant headache lasting about 30 minutes and at least two of the three symptoms: frontalorbital pain, no other accompanying symptoms, and no association with other diseases [5]. This syndrome usually occurs during the takeoff and landing of an aircraft. The cause of this syndrome is presumed to be cerebral vasodilation due to changes in cabin pressure [12]. Taking non-steroidal anti-inflammatory drugs or triptans before the plane takes off reduces the possibility of AHA syndrome. Compressing the head in the area of soreness, performing Valsalva treatments (to equalize pressure in the middle ear) or pulling the earlobes can reduce pain symptoms [12].

7. Acute glaucoma attack (acute CAG - closed angle glaucoma). Acute glaucoma attacks may occur in predisposed eyes during longdistance flying. Such conditions are particularly common in narrow-angle and hyperopic patients. Individuals with a chronic form of CAG should have a prophylactic laser iridotomy procedure performed prior to scheduled long air travel [13].

\section{In which eye diseases is flying contraindicated}

Conditions following retinal surgery with gas injection into the vitreous chamber. The main contraindication for flight in ophthalmic patients is conditions following retinal surgery with gas injection into the vitreous chamber. Under depressurized conditions in the passenger cabin, the gases expand causing a significant increase in intraocular pressure and even a glaucoma attack [6]. This is the opposite of the situation during diving. Airplane flight in these patients is possible after the gas has been completely absorbed. However, there are no contraindications to flight in patients with silicone oil injected into the vitreous chamber during the procedure.

Acute retinal conditions associated with fresh retinal tear, detachment, or hemorrhage into the vitreous. These conditions should be treated with an ophthalmologist prior to scheduled air travel.

A condition following ischemic optic neuropathy. If a patient has been treated in one eye for optic nerve neuropathy there is a greater risk of lesions developing in the other eye during flight. If the cause of neuropathy is temporal arteritis, the risk of neuropathy should be lower if signs of inflammation subside (e.g., normalization of ESR). If the cause is atherosclerosis of the arteries of the optic nerve, the possibility of its occurrence will rather increase with the age of the patient.

Diabetic macular edema. If a patient has diabetic macular edema, there is a risk that the edematous lesions will worsen.

Acute glaucoma with residual visual field. Airplane cabin conditions - lower availability of oxygen, possible pressure fluctuations, etc. - can disrupt both the microcirculation within the nerve II disc and cause increased intraocular pressure (especially in negative $\mathrm{G}(-)$ loads) [10]. These situations can induce vision impairment by damaging retinal ganglion cells through both pressure and hypoxemic means and by loss of residual visual field.

\section{Relative contraindications to airplane flights}

Dry eye syndrome. Passengers with dry syndrome may experience a significant exacerbation of the condition during travel. Therefore, sitting with your eyes closed, frequent use of artificial tears, and shutting the ventilation system off are recommended.

Migraine. Airplane flight can cause the onset or exacerbation of an already existing migraine. This usually occurs during long distance flights. The most likely cause of these conditions is cerebral vasodilatation due to changes in passenger cabin pressure.

Wearing soft contact lenses. Low cabin humidity and high air circulation cause increased evaporation of the mucous-water layer of the tear film, drying of the ocular surface and the onset of dry eye syndrome in contact lens wearers. These symptoms occur primarily in patients who wear soft contact lenses. Wearing glasses rather than lenses during flight and using artificial tears significantly reduce the incidence of these conditions. A solution that may provide partial improvement in in-flight tolerance is to use low-hydration lenses (e.g., silicone hydrogel lenses). 


\section{No contraindications to flying}

The following ocular conditions are not contraindications to flight [1]:

1. Conditions following cataract surgery.

2. Patients with glaucoma, including after antiglaucoma surgery (in addition to the above).

3. Corneal transplants.

4. Other eye surgeries.

5. Ocular inflammatory conditions.

6. Floaters in the vitreous body.

7. Retinal openings and proliferations in the vitreous humor.

8. Posterior vitreous detachment.

\section{Ophthalmic problems that can occur during turbulence or cabin decompression}

The eye conditions outlined above apply when flight is normal. If significant turbulence or decompression of the passenger cabin occurs during it, it may cause surgical wound dehiscence within 2 weeks after surgery due to shock and vomiting [12].

\section{AUTHORS' DECLARATION:}

Study Design: Marek Prost, Krzysztof Kowalczuk, Jaromir Wasyluk; Data Collection: Marek Prost, Krzysztof Kowalczuk, Jaromir Wasyluk; Manuscript Preparation: Marek Prost, Krzysztof Kowalczuk, Jaromir Wasyluk; The Authors declare that there is no conflict of interest.

\section{REFERENCES}

1. American Academy of Ophthalmology: Can I fly with this eye? https://www.aao.org/eye-health/tips-prevention/can-i-fly-with-this-eye

2. Bekö G, Allen JG, Weschler CJ, et al. Impact of cabin ozone concentrations on passenger reported symptoms in commercial aircraft. PLoS One. 2015; 10(5):e0128454.

3. Berilgen MS, Müngen B. A new type of headache, headache associated with airplane travel: preliminary diagnostic criteria and possible mechanisms of aetiopathogenesis. Cephalalgia. 2011; 31(12):1266-1273.

4. Daniele S, Daniele C. Aggravation of laser-treated diabetic cystoid macular edema after prolonged flight: a case report. Aviat Space Environ Med. 1995; 66(5):440-442.

5. Headache Classification Committee of the International Headache Society (IHS). The international classification of headache disorders, 3rd edition (beta version). Cephalalgia. 2013; 33(9):629-808.

6. Houston S, Graf J, Sharkey J. Commercial air travel after intraocular gas injection. Aviat Space Environ Med. 2012; 83(8):809810.

7. Kaiserman I, Frucht-Pery J. Anterior ischemic optic neuropathy after a trans-Atlantic airplane journey. Am J Ophthalmol. 2002; 133(4):581-583.

8. Newsom RS, Trew DR, Leonard TJ. Bilateral buried optic nerve drusen presenting with central retinal artery occlusion at high altitude. Eye (Lond). 1995; 9(Pt 6):806-808.

9. Panos GD, Panos LD, Hafezi F, et al. Ischemic optic neuropathy after a long airplane flight: coincidence or rare economy class syndrome manifestation? Klin Monbl Augenheilkd. 2014; 231(4):390-391.

10. Schwartz R, Stern C, Klemm M, Draeger J, Winter R. Glaukom und Flugtauglichkeit [Glaucoma and aircraft pilot fitness]. Ophthalmologe. 1996; 93(1):76-9.

11. Turgut B, Turgut FA. Neuro-ocular vestibular dysfunction: an overlooked illness. Adv Ophthalmol Vis Syst. 2017; 7(7):476-478.

12. Turgut B. Ocular problems associated air traveling. Adv Ophthalmol Vis Syst. 2018; 8(2):82-83.

13. Turnbull AM, Smith M, Ramchandani M. Angle-closure glaucoma on long-haul flights. JAMA Ophthalmol. 2014; 132(12):1474-5.

Cite this article as: Prost M, Kowalczuk K, Wasyluk J. Ocular Problems Associated With Air Traveling. Pol J Aviat Med Bioeng Psychol 2019; 25(3): 22-25. DOI: 10.13174/pjambp.15.04.2021.03 